\title{
Patient Requests Pregnancy Termination
}

National Cancer Institute

\section{Source}

National Cancer Institute. Patient Requests Pregnancy Termination. NCI Thesaurus.

Code C137945.

An indication that a patient requests to terminate pregnancy. 